\title{
Cognitive Assessment in Adult Cardiac Arrest Survivors: What Is Known and How Shall We Move Forward?
}

Han Shi Jocelyn CHEW, RN, BSN (Hons), PhD Candidate ${ }^{a}$, Ho Yu CHENG, RN, PhD ${ }^{b}, X i C A O$, $P h D^{c}$, and Violeta LOPEZ, RN, PhD, FACN ${ }^{d}$

Background: Cardiac arrest (CA) remains the leading cause of premature deaths. Survivors often suffer from ischaemia-reperfusion injuries, which lead to neurological damage, cognitive impairment and psychosocial problems. While most survivors have to be assessed and deemed neurologically and functionally fit enough before discharge, adequacy of cognitive function is often neglected. This leads to problems with memory, attention, and executive function that are important for daily living. Aim: This study aims to provide an overview of existing literature regarding the use of cognitive assessment in adult CA survivors. Methods: $A$ scoping review was conducted. Results/Findings: 62 articles were included and the existing relevant literature on the use of cognitive assessment can be mapped into the following themes: neurological-cognitive-psychosocial sequelae, effects of therapeutic hypothermia, prediction of cognitive function, adequacy of cognitive assessment tools, and effectiveness of post-CA rehabilitation interventions with cognitive domain. There is currently no consensus on the cognitive screening tool for cardiac arrest survivors although it is clear that they suffer from cognitive impairments especially memory and executive function. Conclusion: Routine cognitive testing should be part of follow-up care especially alongside cardiac rehabilitation to enhance patient outcomes and secondary prevention through complex self-care. This may decrease mortality, morbidity, and disease burden on an individual, national, and even global level.

Keywords: cognitive; scoping; cardiac arrest; rehabilitation; OHCA

\section{INTRODUCTION}

Cardiac arrest (CA) refers to the sudden cessation of the heart's ability to pump blood around the body, resulting in mortality and morbidity (Mozaffarian et al., 2016). Out-of-hospital CA (OHCA) survival-to-discharge (STD) rates remains low from $2 \%$ in Asia, $9 \%$ in Europe, $6 \%$ in North America, and 11\% in Australia (Berdowski et al., 2010), while that of in-hospital CA (IHCA)
STD was $22 \%$ in the United States and $11.8 \%$ in Taiwan (Chen et al., 2016; Girotra, Chan, \& Bradley, 2015). Although prompt resuscitation improves survival upon return of spontaneous circulation (ROSC), studies have shown that survivors suffer from postcardiac arrest syndrome (PCAS), including neurological and cognitive impairments caused by ischemia and reperfusion during and after resuscitation (Jentzer

\footnotetext{
${ }^{a}$ PhD Candidate, The Nethersole School of Nursing, Faculty of Medicine, The Chinese University of Hong Kong, Hong Kong SAR, China. Email: jocelyn.chew.hs@link.cuhk.edu.hk

${ }^{b}$ Assistant Professor, The Nethersole School of Nursing, Faculty of Medicine, The Chinese University of Hong Kong, Hong Kong SAR, China

${ }^{c}$ Postdoctoral Fellow, The Nethersole School of Nursing, Faculty of Medicine, The Chinese University of Hong Kong, Hong Kong SAR, China

${ }^{d}$ Professor, Alice Lee Centre for Nursing Studies, Yong Loo Lin School of Medicine, National University of Singapore, Singapore
} 
et al., 2016; Nolan, Perkins, \& Soar, 2015). About $30 \%$ to $80 \%$ of survivors sustain diffused brain injury that contributes to high mortality, neurocognitive deficits, functional disabilities, lower health-related quality of life (HR-QoL), lower psychosocial well-being, and lower emotional well-being (Moulaert et al., 2013; Ketilsdottir, Albertsdottir, Akadottir, Gunnarsdottir, \& Jonsdottir, 2014; Polanowska et al., 2014; Whitehead, Perkins, Biggerstaff, Couper, \& Haywood, 2015).

With advanced technology such as the use of extracorporeal membrane oxygenation (ECMO), CA mortality in countries with higher promotion and training of cardiopulmonary resuscitation (CPR) has and will continue to decrease over the years (75\%-44\%) (Haydon, Riet, \& Maguire, 2017). However, in spite of interventions such as therapeutic hypothermia (TH) to preserve neurological function, long-term post-CA cognitive impairments and how they affect daily living even after $\mathrm{TH}$ remains ambiguous. A systematic review of 70 studies on the HR-QoL in CA survivors found that health-related HR-QoL was acceptable in majority of the reports but methodologies were heterogeneous and not all included cognitive domain as part of HR-QoL (Elliott, Rodgers, \& Brett, 2011). The authors also warned that there were stark differences in the patients' and carer's report on disabilities and activities of daily living, possibly leading to inaccurate findings. Although HR-QoL post-CA is mostly acceptable, this should not stop efforts to regain cognitive function specially to perform behaviors and tasks important to maintain one's well-being (e.g., adopting healthy lifestyle to prevent heart failure, a common final condition of cardiovascular illnesses). A systematic review of 28 studies on the cognitive impairments in OHCA survivors revealed that the reported frequency of cognitive impairments ranged from $6 \%$ to $100 \%$, with impairment in memory, attention, and executive function in decreasing order (Moulaert, Verbunt, van Heugten, \& Wade, 2009). This concurs with the study by Perez, Samudra, and Aiyagari (2016), which also highlighted the importance of developing interventions that improve cognitive and psychosocial aspects of post-CA survivors and a standardized comprehensive cognitive assessment for early and more targeted interventions. As post-CA survival rates continue to improve, this warrants the assessment of not only survival but also the cognitive ability as an outcome to inform rehabilitation interventions including self-care. However, it is nonroutinely assessed upon discharge possibly due to the lack of understanding of the current state of the art knowledge on it. Therefore, this paper aims to provide a scoping review that maps what is known on and has been done regarding cognitive assessment in adult CA survivors to inform further interventions to enhance patient outcomes besides survival.

\section{METHODS}

A scoping review was conducted to map the range of research activities available, findings and research gaps to inform further research including the feasibility of conducting a systematic review. As the paper is purposed to provide an overview of what has been done in this research field of interest, methodological appraisals are not performed in scoping reviews (Peters et al., 2015). To ensure rigor, the review was conducted systematically according to the framework by Arksey and O'Malley (2005), which consists of five stages as described below:

Stage 1: Identifying the research question. This review aims to summarize the available literature on the use of cognitive assessment in adult CA survivors by answering the question: What is known about the use of cognitive assessment in adult CA survivors?

Stage 2: Identifying relevant studies. A systematic three-step search strategy was employed. Firstly, keywords were derived from an initial search of CINAHL and PubMed. To enhance sensitivity of the search, more keywords were generated using Medical Subject Heading (MESH) browser. Secondly, a systematic search from four 
electronic databases namely CINAHL, PubMed, EMBASE, and Cochrane Library within January 2000 to December 2017 was conducted to maintain comprehensive and updated knowledge retrieved. Keywords were combined using Boolean operators, AND or OR (cognitive assessment, cognitive evaluation, cognitive test, cognitive measure*) (Table 1). Thirdly, a manual search on the reference lists of the shortlisted articles was performed to identify more relevant articles.

Stage 3: Study selection. Articles were included if they met the following inclusion criteria: (1) focused on cognition in CA survivors; (2) used cognitive assessment tools; (3) full-texts available in English; and (5) published within the period from January 2000 to December 2017. Articles were excluded if they focused on patients with implanted devices, hospital coding, clinical competencies, and resuscitation preferences. Grey literature was also included in the search.

Stage 4: Charting the data. Relevant data was extracted and charted according to the following categories: Author(s)/year of publication/country; study design; aim; sample characteristics; setting; methodology; cognitive tests used; time frame of study since CA event; outcome; and key

TABLE 1. Search terms

\begin{tabular}{|c|c|c|}
\hline Database & Searches keywords & No. of articles found \\
\hline CINAHL & $\begin{array}{l}\text { TX ( (cognitive assessment) or (cognitive evaluation) } \\
\text { or (cognitive test) or (cognitive measure*)) AND TX } \\
\text { (cardiac arrest or heart arrest or cardiopulmonary } \\
\text { arrest) }\end{array}$ & 225 \\
\hline PubMed & $\begin{array}{l}\text { ((("cognitive"[All Fields]) AND ("assessment"[All } \\
\text { Fields])) OR (("cognitive"[All Fields]) AND } \\
\text { ("evaluation studies"[Publication Type] OR } \\
\text { "evaluation studies as topic"[MeSH Terms] OR } \\
\text { "evaluation"[All Fields])) OR (("cognitive"[All Fields]) } \\
\text { AND ("research design"[MeSH Terms] OR } \\
\text { ("research"[All Fields] AND "design"[All Fields]) OR } \\
\text { "research design"[All Fields] OR "test"[All Fields])) } \\
\text { OR (cognitive measure[All Fields] OR cognitive } \\
\text { measurement[All Fields] OR cognitive } \\
\text { measurements[All Fields] OR cognitive measures[All } \\
\text { Fields])) AND (("heart arrest"[MeSH Terms] OR } \\
\text { ("heart"[All Fields] AND "arrest"[All Fields]) OR } \\
\text { "heart arrest"[All Fields] OR ("cardiac"[All Fields] } \\
\text { AND "arrest"[All Fields]) OR "cardiac arrest"[All } \\
\text { Fields]) OR ("heart arrest"[MeSH Terms] OR } \\
\text { ("heart"[All Fields] AND "arrest"[All Fields]) OR } \\
\text { "heart arrest"[All Fields]) OR ("heart arrest"[MeSH } \\
\text { Terms] OR ("heart"[All Fields] AND "arrest"[All } \\
\text { Fields]) OR "heart arrest"[All Fields] OR } \\
\text { ("cardiopulmonary"[All Fields] AND "arrest"[All } \\
\text { Fields]) OR "cardiopulmonary arrest"[All Fields])) }\end{array}$ & 171 \\
\hline EMBASE & $\begin{array}{l}\text { ((cognitive assessment or cognitive evaluation or } \\
\text { cognitive test or cognitive measure*) and (cardiac } \\
\text { arrest or heart arrest or cardiopulmonary arrest)).af. }\end{array}$ & 22 \\
\hline $\begin{array}{l}\text { Cochrane } \\
\text { Library }\end{array}$ & $\begin{array}{l}\text { (cognitive assessment) or (cognitive evaluation) or } \\
\text { (cognitive test) or (cognitive measure*) and cardiac } \\
\text { arrest or heart arrest or cardiopulmonary arrest }\end{array}$ & 171 \\
\hline
\end{tabular}


findings related to the scoping review question. The data chart was tested on two random papers to ensure its suitability in extracting relevant data from the included articles. The data chart was found to be suitable and no further changes were made.

Stage 5: Collating, summarizing, and reporting the results. Data were collated and summarized numerically, thematically analysed according to nature of the articles, and reported descriptively in terms of general and specific aspects of the literature.

\section{RESULTS}

Sixty-two articles were included in the review and the systematic selection of articles is presented according to the PRISMA flow diagram (Figure 1 ). The existing literature on the use of cognitive assessment can be conceptually mapped into themes namely to find out: neurologicalcognitive-psychosocial sequelae, effects of $\mathrm{TH}$, prediction of cognitive function, adequacy of cognitive assessment tools, and effectiveness of postCA rehabilitation interventions with cognitive domain (Figure 2).

\section{Neurological-Cognitive-Psychosocial Sequelae} Overall, the commonly practiced predischarge neurological and functional status assessment are Cerebral Performance Category (CPC) and modified Ranking Scale (mRS) (Mak, Moulaert, Pijls, \& Verbunt, 2016; Rittenberger, Raina, Holm, Kim, \& Callaway, 2011). Survivors of CA often sustain diffused hypoxic injury in the cortex, subcortical and hippocampal brain regions, resulting in neurological symptoms ranging from primary tremors, tics, and seizures to secondary brain injury including dementia, Parkinson's syndrome, and paresis (Polanowska et al., 2014). Up to $95 \%$ of long-term survivors of CA have good neurological and functional status upon discharge as indicated by the CPC $(\leq 2)$ and exercise capacity $\left(\mathrm{VO}_{2}\right.$ peak) but half of them experience cognitive impairments during the first year postdischarge (Boyce et al., 2017; Cronberg \& Lilja, 2015; Nunes et al., 2003; Sulzgruber et al., 2015).
Cognitive impairment includes memory (special, verbal, recall), executive function, attention, language, and visuospacial/orientation impairments (ranked from most to least common and severe) (Anderson \& Arciniegas, 2010; Howard, Holmes, \& Koutroumanidis, 2011; Lim, Alexander, LaFleche, Schnyer, \& Verfaellie, 2004; Polanowska et al., 2014; Steinbusch et al., 2017). Studies have produced mixed results on the presence and persistence of cognitive impairments. While Polanowska et al. (2014) reported that above $50 \%$ of OHCA survivors had persistent cognitive impairments upon 12 months after OHCA and above 30\% were significantly disabled, Beesems et al. (2014) reported normal cognition and functioning 6 to 12 months after OHCA. This could be due to the problem of not having a standardized test for functional and cognitive status. Recovery of memory and visuospacial impairment has been shown to be limited to the first three months while that of executive function is more prolonged over 3 to 10 months (Steinbusch et al., 2017).

Mixed results were obtained regarding the psychosocial sequela including caregiver strain (Beesems et al., 2014; Pusswald, Fertl, Faltl, \& Auff, 2000), decreased quality of life (Buanes et al., 2015; Middelkamp et al., 2007; Nichol et al., 2015), decreased work capacity, decreased independence in daily living, decreased social participation, depression, anxiety, and fatigue (Lilja et al., 2015; Moulaert, van Heugten, Gorgels, Wade, \& Verbunt, 2017; Whitehead et al., 2015). Most studies reported nonsignificant association between depression and anxiety with cognitive impairment (Davies et al., 2017) Contrarily, Hofgren, Lundgren-Nilsson, Esbjörnsson, \& Sunnerhagen, (2008) reported that cognitive impairment was associated with anxiety especially in males and younger survivors but not depression. Interestingly, this is true even for a study that reported good HR-QoL (Lundgren-Nilsson, Rosen, Hofgren \& Sunnerhagen, 2005). Therefore, more research is needed to substantiate these findings (Dostálová et al., 2016). 
Figure 1. Flow diagram of literature search.

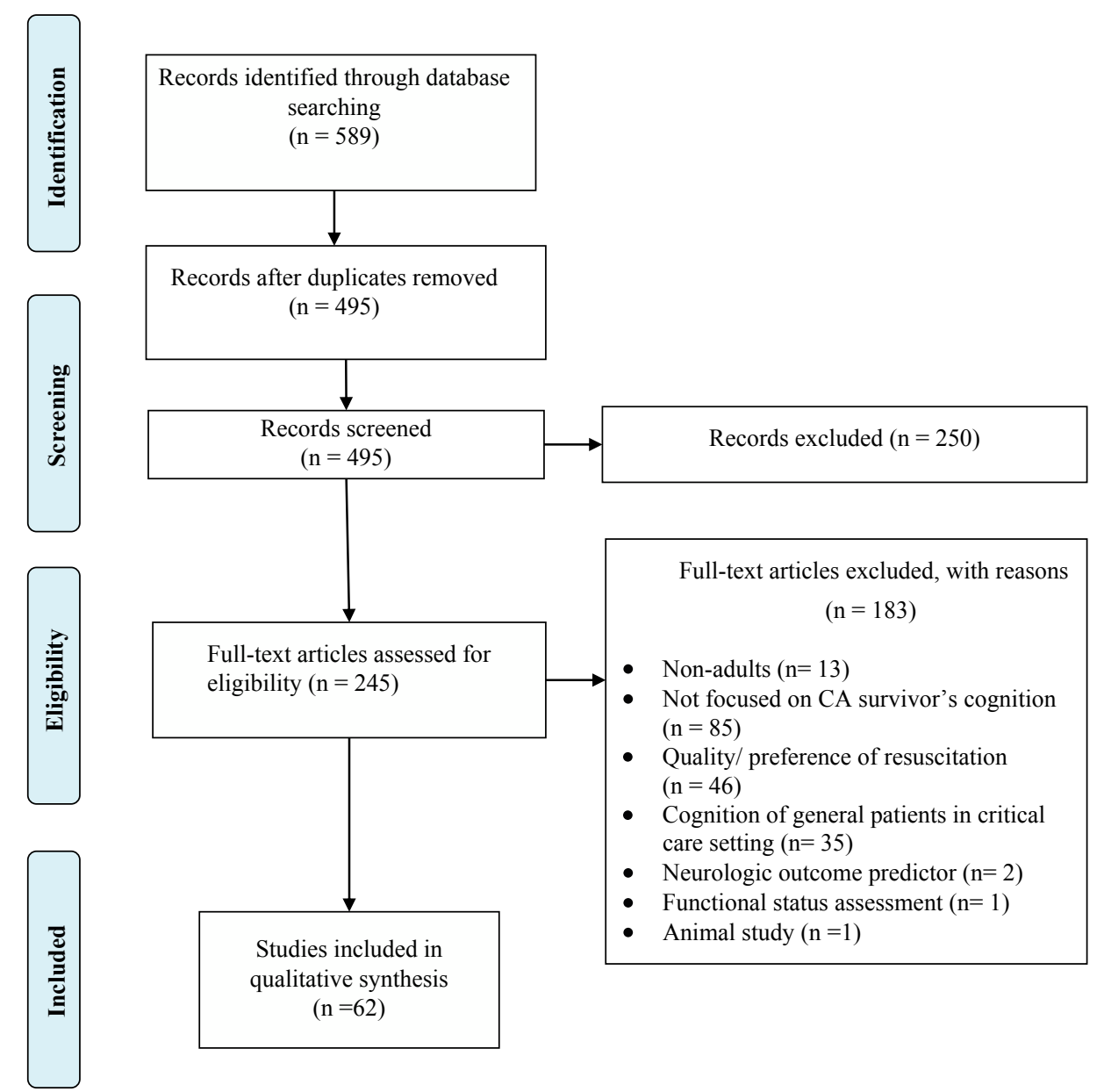

Figure 2. Map of results.

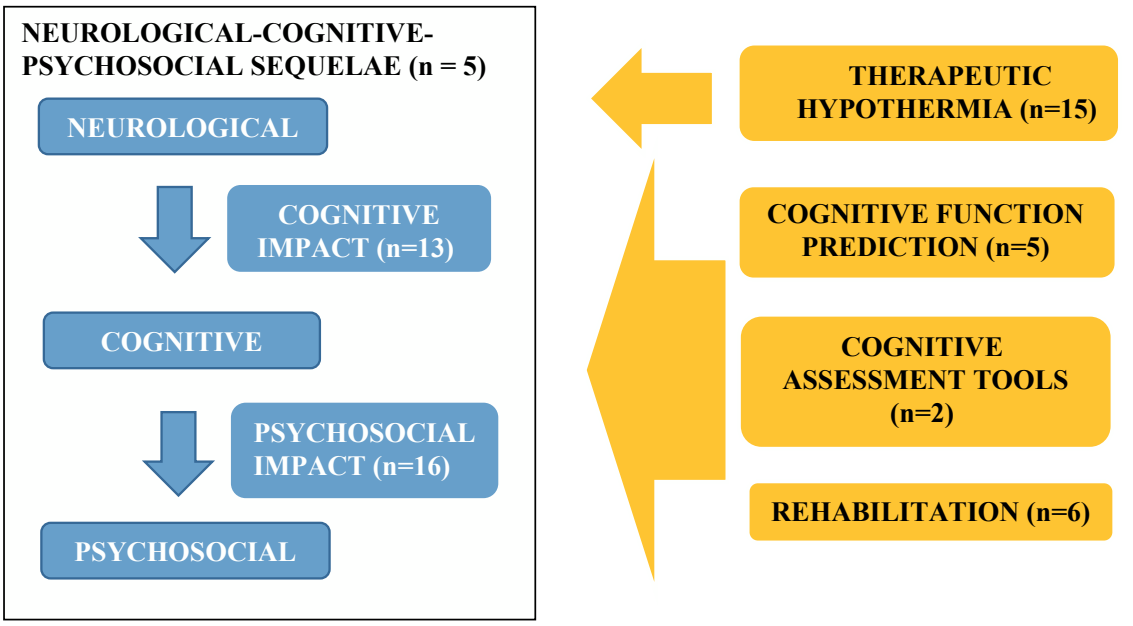




\section{Therapeutic Hypothermia}

$\mathrm{TH}$ has been shown to increase survival by $30 \%$ to $50 \%$ by reducing cerebral metabolism, cerebral oxygen demand, cerebral ischaemia, and preventing excitotoxicity (Arrich, Holzer, Havel, Müllner, \& Herkner, 2012; Karnatovskaia, Wartenberg, \& Freeman, 2014). While its acute benefits are clear, chronic effect from the ischemia reperfusion event remains unclear especially in terms of cognitive function (Karnatovskaia et al., 2014; Torgersen et al., 2010). Although studies have shown mixed results on the effectiveness of $\mathrm{TH}$ in preserving cognitive function, most report that cognitive function does not significantly affect HR-QoL and performance of activities of daily living (Cronberg, Lilja, Rundgren, Friberg, \& Widner, 2009; Fugate et al., 2013; Tiainen et al., 2015). Additionally, Cronberg et al. (2015) reported that standard outcome scales such as CPC and mRS did not detect certain cognitive impairments detected during the study that used Mini-Mental State Examination (MMSE), suggesting the need for a more specific and sensitive measure for cognitive function.

\section{Predictions of Cognitive Impairment}

Risk prediction of cognitive impairment is crucial in planning for rehabilitation. Protein serum S100B has been widely studied and recommended as a reliable (specificity and sensitivity index were more than 90\%) early predictor of OHCA survivors at risk of short and long-term cognitive impairments especially that of memory function (Grubb et al., 2007; Lippi, Aloe, Numeroso, \& Cervellin, 2011; Prohl, Bodenburg, \& Rustenbach, 2009; Prohl et al., 2007). However, further replication in larger trials and a more diverse demographic population is needed. Duration of impaired consciousness and memory post-CA was shown to predict long-term cognitive impairments (more than three months) including memory, attention and executive function (Dostálová et al., 2016; Ørbo et al., 2014).

\section{Types of Cognitive Assessment Tools Used}

Unfortunately, no gold standard is available as a cognitive screening for CA survivors, which is not routinely assessed in the first place possibly due to the extensive and time-consuming nature of a neuropsychological test. A commonly used cognitive screening tool is the MMSE which is fast and easy to complete but has a ceiling effect and insensitivity when used in patients without dementia (Boyce et al., 2017; Koller et al., 2017), Iannacone et al. (2014) developed a computerized neurocognitive battery (CNB) that was tested for feasibility in patients with CPC score of 1 and was shown to be specific enough to detect cognitive deficits. It included tests for accuracy and speed on neurocognitive domains including working and episodic memory, abstraction and mental flexibility, reasoning, and processing. Koller et al. (2017) compared the diagnostic accuracy of three cognitive assessment tools, Computer Assessment of Mild Cognitive Impairment (CAMCI), the Montreal Cognitive Assessment (MOCA), and the 41 Cent Test (41CT) on CA survivors who scored low on the MMSE and found that CAMCI was most accurate. However, its computerized nature requires additional facilitators supervision, is more time-consuming and physically demanding hence may not be clinically feasible as a bedside or predischarge cognitive screening tool. The three tools were moderately to very strongly correlated with each other, especially in executive function scores which highlights the importance of targeting its improvement when planning for rehabilitation (Steinbusch et al., 2017). Other tools used to assess different components are shown in Table 2.

\section{Rehabilitation}

The importance of including cognitive and psychosocial component in post-CA rehabilitation in addition to physical recuperation through cardiac rehabilitation was highlighted as the "missing link" (Boyce \& Goossens, 2017). As most clinicians are not trained to detect cognitive impairments especially mild ones, survivors with cognitive impairment may display difficulties in following instructions and require repeated instructions, passing off as being unmotivated. Moulaert et al. (2015) tested the effectiveness of early detection and management of 
TABLE 2. Cognitive tests used

\begin{tabular}{ll}
\hline Tests & Cognitive domains tested \\
\hline MMSE & $\begin{array}{l}\text { Orientation, memory, concentration, } \\
\text { language and praxis } \\
\text { Cognitive Failure } \\
\text { Questionnaire }\end{array}$ \\
IQCODE & $\begin{array}{l}\text { Memory and attention } \\
\text { living and compares the present and previous } \\
\text { functioning before and after cardiac arrest }\end{array}$ \\
CANTAB & $\begin{array}{l}\text { Working memory, learning, and executive } \\
\text { function; visual, verbal, and episodic memory; } \\
\text { attention, information processing, and } \\
\text { reaction time; social and emotion recognition, } \\
\text { decision making, and response control }\end{array}$
\end{tabular}

CAMCI

Cognitive Log (Cog-Log)

Wechsler Abbreviated Scale of Intelligence matrix and block testing

American National Adult

Reading Test

BNIS

CNB

Digit Span test (Wechsler Intelligence Scale WAIS-R[PI] and can be used independently due to its standardization)

RAVLT

Rey Auditory and Verbal Learning Test

Rey's complex Figure Test

California Verbal Learning Test II

Wechsler Memory Scale
Attention, executive abilities, working memory, and verbal and visual memory

General cognitive abilities

Verbal, nonverbal and general cognitive ability (IQ)

Performance IQ score

Speech and language functions, orientation, attention, visual spatial and visual problem-solving, memory, affect and awareness of performance

Executive control, episodic memory, complex cognition, social cognition

Memory and resistance to distractors interfering with the concentration of awareness

Immediate, delayed free recall, and recognition in several ways

Learning and memory

Visuo-spatial ability, short- and long-term visual memory (copy-trial, immediate recall, delayed recall, and visual recognition)

Verbal learning, memory interference, shortand long-term memory and long-term recognition

Attention and working memory 
TABLE 2. Cognitive tests used (Continued)

\begin{tabular}{|c|c|}
\hline Tests & Cognitive domains tested \\
\hline $\begin{array}{l}\text { Memory Span: Verbal- and } \\
\text { Visual span, both forwards and } \\
\text { backwards }\end{array}$ & Attention and working memory \\
\hline $\mathrm{RBMT}$ & Memory \\
\hline Brief visual memory test & Memory \\
\hline Red-Pencil-Test & Prospective memory \\
\hline $\begin{array}{l}\text { Logical memory subscale from } \\
\text { WMS-R }\end{array}$ & Prose recall \\
\hline Verbal Fluency Test & Semantic memory and word fluency \\
\hline $\mathrm{PR}$ & Short-term and delayed verbal memory \\
\hline BVRT & Visual perception and visual memory \\
\hline $\begin{array}{l}\text { Benton Judgement of Line } \\
\text { Orientation Test }\end{array}$ & Perception \\
\hline $\begin{array}{l}\text { Number location subtest from } \\
\text { visual object and space } \\
\text { pereption battery }\end{array}$ & Perception \\
\hline $\begin{array}{l}\text { benton visual discrimination } \\
\text { test }\end{array}$ & Perception \\
\hline Trail Making Test B & Executive function \\
\hline Winsconsin card sorting test & Executive function \\
\hline Animal generations & Executive function \\
\hline Stroop Test & Executive function \\
\hline Frontal Assessment Battery & Executive function \\
\hline $\begin{array}{l}\text { D-K Executive Functioning } \\
\text { System }\end{array}$ & Executive function \\
\hline D-K Color-Word & $\begin{array}{l}\text { Executive functioning. Selective attention and } \\
\text { response inhibition }\end{array}$ \\
\hline D-K Verbal Fluency & $\begin{array}{l}\text { Executive functioning, rapid word generation } \\
\text { and verbal flexibility }\end{array}$ \\
\hline Boston naming test from $\mathrm{BDAE}$ & Language \\
\hline $\begin{array}{l}\text { Word comprehension from } \\
\text { BDAE }\end{array}$ & Language \\
\hline Word reading from $\mathrm{BDAE}$ & Language \\
\hline $\begin{array}{l}\text { Controlled Oral Word } \\
\text { Association Test for verbal } \\
\text { fluency and additional tests for } \\
\text { category fluency }\end{array}$ & Language \\
\hline
\end{tabular}

(Continued) 
TABLE 2. Cognitive tests used (Continued)

\begin{tabular}{ll}
\hline Tests & Cognitive domains tested \\
\hline Trail Making Test A & Psychomotor functioning \\
grooved pegboard & Fine motor functioning \\
finger tapping (dominant & Motor functioning \\
hand) & Ability to maintain attention and mental speed \\
SDMT & Speed of information processing \\
AMIPB Task A (information & \\
processing speed) & $\begin{array}{l}\text { Ability to see and recognize patterns, to } \\
\text { understand relations between elements of the } \\
\text { pauretta Bender's } \\
\text { Visual-Motor Gestalt Test }\end{array}$ \\
& skills, and the integration of those abilities \\
\hline
\end{tabular}

Notes: AMIPB, The Adult Memory and Information Processing Battery; BDAE, boston doagnostic aphasia exam; BNIS, Barrow Neurological Institute Screen for Higher Cerebral Functions; BVRT, Benton Visual Retention Test; CAMCI, Computer Assessment of Mild Cognitive Impairment; CANTAB, Cambridge Neuropsychological Test Automated Battery; CNB, computerized neurocognitive battery; D-K, Delis-Kaplan; IQCODE, Informant Questionnaire on Cognitive Decline in the Elderly; MMSE, MiniMental State Examination; PR, Paragraph Recall; RAVLT, Rey Adult Verbal Learning Test; RBMT, Rivermead Behavioral Memory Test; SDMT, Symbol Digit Modalities Test; WMS-R, Wechsler Memory Scale-Revised.

cognitive and emotional effects of CA. The nursing intervention was shown to be cost effective and significantly improved HR-QoL, mental health, general health, emotional state, anxiety, despite not showing significant improvements in cognition (Moulaert, Goossens, Heijnders, Verbunt, \& van Heugten, 2016). Nevertheless, this suggests the effectiveness of early detection of cognitive impairment and psychosocial interventions on improving CA survivors' psychosocial well-being. Similarly, Cowan, Pike, \& Budzynski (2001) reported significant reduction in allcause mortality (62\%) in participants who received a psychosocial nursing therapy that included 11 individual sessions that included components of physiological relaxation, biofeedback training targeted at altering autonomic tone, cognitive behavior therapy, self-management, coping with emotions and education. Existing post-CA cardiac rehabilitation focuses on physical recuperation to enhance functional outcomes and the neglect of a cognitive component may be due to research findings that cognitive impairment does not have significant impact of functional status and HR-QoL.
Nevertheless, more research is warranted to confirm this finding.

\section{DISCUSSION}

Existing literature was categorized into five themes, presenting a comprehensive overview of what has been done on the research field of cognitive assessment in CA survivors. While the neurological-cognitive-psychosocial sequelae seems clear and established, more research is needed to confirm the psychosocial impact of cognitive impairment in CA survivors. TH has been a popular research interest due to its neuroprotective potential to alleviate the sequelae from the neurological level. However, its uptake in Asian countries remains low, warranting more research to establish the generalisability of its benefits (Ong et al., 2015, Fan, Leung, \& Siu, 2017). Predictors, predischarge and follow-up assessment of cognitive impairment is important for rehabilitation planning, which is important for CA survivors to return to their pre-CA psychosocial and physical function status. 
Most studies have shown that an acceptable CPC score predischarge does not necessarily predict acceptable cognitive function and that cognitive impairment does not necessarily lower CA survivors' HR-QoL. This could be due to the nature of tools used to access HR-QoL, commonly the SF-36, which does not include a cognitive domain. This is supported by a study on the cognitive function and HR-QoL in individuals 4 years post-CA using the Cambridge Neuropsychological Test Automated Battery (CANTAB), where 29\% with good CPC upon discharge had persistent cognitive impairments specifically in shortterm memory and executive function (Buanes et al., 2015). However, the authors warned that that actual rates of cognitive impairment may be higher due to higher mortality rates in these individuals.

As most study show that the mild cognitive impairment post-CA is unlikely to significantly affect functional status, it is possible that the mild cognitive impairment may have a stronger negative effect on one's return-to-work if it requires more cognitive ability especially that in memory, attention and executive function such as working as an analyst as compared to performing activities of daily living. However, further studies are warranted to explore the effects of cognitive impairment post-CA in patients stratified according to age, education level, occupational cognitive demands.

Almost all studies emphasized on the importance of early bedside neuropsychological screening to plan for neurocognitive rehabilitation and aid post-CA in addition to the existing cardiac rehabilitation that focuses on physical outcomes (Boyce-van der Wal et al., 2015). This includes passive physiotherapy, sensory stimulation, deep brain stimulation, occupational therapy, cognitive rehabilitation, progressive training, compensatory strategy development, cognitive prosthetics (e.g., visual reminders, task lists), environmental modification and behavioral adaptation (Anderson \& Arciniegas, 2010; Polanowska et al., 2014). However, it is still not routinely practiced. The main concern of implementing cognitive assessment into routine pre-discharge and follow-up assessment may be the long neuropsychological testing time, sensitivity and specificity of the assessment tools. Additionally, scores on these tools may be confounded by factors such as age, comorbidities and stress instead of just the ischaemia-reperfusion brain injury during CA.

From the review of the literature included in this scoping review, challenges in uncovering this phenomenon include higher mortality associated with post-CA survivors with cognitive impairment, short study time-frame, heterogeneity in reporting, measuring and sample characteristics and no standardized measure for cognitive assessment (Perez et al., 2016). Moreover, the generalisability of the findings is further limited by the lack of Asia studies, and small sample size.

\section{CONCLUSION}

As CA survival continues to increase, there is a need to improve rehabilitation services to not only focus on physical recuperation but also the cognitive and psychosocial aspect of survivors' lives. More studies are needed to find out the impact of cognitive impairment on other domains of one's life such as return-to-work performance and the difference in its effect on different sociodemographic profiles especially in Asians. This would contribute to better long-term outcomes through secondary prevention such as self-care, reducing morbidity, mortality, and healthcare expenditure.

\section{References}

Anderson, C. A., \& Arciniegas, D. B. (2010). Cognitive sequelae of hypoxic-ischemic brain injury: A review. NeuroRehabilitation, 26(1), 47-63.

Arksey, H., \& O’Malley, L. (2005). Scoping studies: Towards a methodological framework. International Journal of Social Research Methodology, 8(1), 19-32. doi:10.1080/ 1364557032000119616 
Arrich, J., Holzer, M., Havel, C., Müllner, M., \& Herkner, H. (2012). Hypothermia for neuroprotection in adults after cardiopulmonary resuscitation. Cochrane Database Systematic Review, 9(9), 1-34. doi:10.1002/ 14651858.CD004128.pub3

Beesems, S. G., Wittebrood, K. M., Haan de, J. R., \& Koster, R. W. (2014). Cognitive function and quality of life after successful resuscitation from cardiac arrest. Resuscitation, 85(9), 1269-1274. doi:10.1016/ j.resuscitation.2014.05.027

Berdowski, J., Berg, R. A., Tijssen, J. G., \& Koster, R. W. (2010). Global incidences of outof-hospital cardiac arrest and survival rates: systematic review of 67 prospective studies. Resuscitation, 81(11), 1479-1487.

Boyce, L. W., \& Goossens, P. H. (2017). Rehabilitation after cardiac arrest: Integration of neurologic and cardiac rehabilitation. Seminars in neurology, 37(1), 094-102. doi:10.1055/ s-0036-1593860

Boyce, L. W., Reinders, C. C., Volker, G., Los, E., van Exel, H. J., Vlieland, T. P. V., \& Goossens, P. H. (2017). Out-of-hospital cardiac arrest survivors with cognitive impairments have lower exercise capacity. Resuscitation, 115, 90-95. doi:10.1016/ j.resuscitation.2017.04.010

Boyce-van der Wal, L. W., Volker, W. G., Vlieland, T. V., van den Heuvel, D. M. J., \& Goossens, P. H. (2015). Cognitive problems in patients in a cardiac rehabilitation program after an out-ofhospital cardiac arrest. Resuscitation, 93, 6368. doi:10.1016/j.resuscitation.2015.05.029

Buanes, E. A., Gramstad, A., Søvig, K. K., Hufthammer, K. O., Flaatten, H., Husby, T., . . . Heltne, J. K. (2015). Cognitive function and health-related quality of life four years after cardiac arrest. Resuscitation, 89, 13-18. doi:10.1016/j.resuscitation.2014.12.021

Chen, C. T., Chiu, P. C., Tang, C. Y., Lin, Y. Y., Lee, Y. T., How, C. K., \& Huang, M. S. (2016). Prognostic factors for survival outcome after in-hospital cardiac arrest: An observational study of the oriental population in Taiwan. Journal of the Chinese Medical Association,
79(1), 11-16. doi:10.1016/j.jcma.2015.07.011 Cowan, M. J., Pike, K. C., \& Budzynski, H. K. (2001). Psychosocial nursing therapy following sudden cardiac arrest: Impact on two-year survival. Nursing Research, 50(2), 68-76. doi:10.1097/00006199-200103000-00002

Cronberg, T., \& Lilja, G. (2015). Cognitive decline after cardiac arrest-It is more to the picture than hypoxic brain injury. Resuscitation, 91, A3-A4. doi:10.1016/ j.resuscitation.2015.03.002

Cronberg, T., Lilja, G., Horn, J., Kjaergaard, J., Wise, M. P., Pellis, T., \& Erlinge, D. (2015). Neurologic function and health-related quality of life in patients following targeted temperature management at $33^{\circ} \mathrm{C}$ vs $36^{\circ} \mathrm{C}$ after out-of-hospital cardiac arrest: A randomized clinical trial. Journal of American Medical Association Neurology, 72(6), 634-641. doi:10.1001/jamaneurol.2015.0169

Cronberg, T., Lilja, G., Rundgren, M., Friberg, H., \& Widner, H. (2009). Long-term neurological outcome after cardiac arrest and therapeutic hypothermia. Resuscitation, $80(10)$, 1119-1123. doi:10.1016/ j.resuscitation.2009.06.021

Davies, S. E., Rhys, M., Voss, S., Greenwood, R., Thomas, M., \& Benger, J. R. (2017). Psychological wellbeing in survivors of cardiac arrest, and its relationship to neurocognitive function. Resuscitation, 111, 22-25. doi:10.1016/j.resuscitation.2016.11.004

Dostálová, V., Sedláček, K., Bělohlávek, J., Turek, R., Pretl, M., \& Bezdicek, O. (2016). Psychosocial sequelae following cardiac arrest. Cor et Vasa, 59(3), e222-e228. doi:10.1016/ j.crvasa.2016.11.012

Elliott, V. J., Rodgers, D. L., \& Brett, S. J. (2011). Systematic review of quality of life and other patient-centred outcomes after cardiac arrest survival. Resuscitation, 82(3), 247256. doi:10.1016/j.resuscitation.2010.10.030

Fan, K. L., Leung, L. P., \& Siu, Y. C. (2017). Out-of-hospital cardiac arrest in Hong Kong: A territory-wide study. Hong Kong Medical Journal, 23(1), 48-53. doi:10.12809/ hkmj166046 
Fugate, J. E., Moore, S. A., Knopman, D. S., Claassen, D. O., Wijdicks, E. F., White, R. D., \& Rabinstein, A. A. (2013). Cognitive outcomes of patients undergoing therapeutic hypothermia after cardiac arrest. Neurology, 81(1), 40 45. doi:10.1212/WNL.Ob013e318297ee7e

Girotra, S., Chan, P. S., \& Bradley, S. M. (2015). Post-resuscitation care following out-ofhospital and in-hospital cardiac arrest. Heart, 101(24), 1943-1949. doi:10.1136/heartjnl2015-307450

Grubb, N. R., Simpson, C., Sherwood, R. A., Abraha, H. D., Cobbe, S. M., O'carroll, R. E., \& Fox, K. A. (2007). Prediction of cognitive dysfunction after resuscitation from out-of-hospital cardiac arrest using serum neuron-specific enolase and protein S-100. Heart, 93(10), 1268-1273. doi:10.1136/ hrt.2006.091314

Haydon, G., Riet, P., \& Maguire, J. (2017). Survivors' quality of life after cardiopulmonary resuscitation: An integrative review of the literature. Scandinavian Journal of Caring Sciences, 31(1), 6-26. doi:10.1111/scs.12323

Hofgren, C., Lundgren-Nilsson, А., Esbjörnsson, E., \& Sunnerhagen, K. S. (2008). Two years after cardiac arrest; cognitive status, ADL function and living situation. Brain Injury, 22(12), 972-978. doi:10.1080/ 02699050802491289

Howard, R. S., Holmes, P. A., \& Koutroumanidis, M. A. (2011). Hypoxic-ischaemic brain injury. Practical Neurology, 11(1), 4-18. doi:10.1136/jnnp.2010.235218

Iannacone, S., Leary, M., Esposito, E. C., Ruparel, K., Savitt, A., Mott, A., \& Abella, B. S. (2014). Feasibility of cognitive functional assessment in cardiac arrest survivors using an abbreviated laptop-based neurocognitive battery. Therapeutic Hypothermia and Temperature Management, 4(3), 131-136. doi:10.1089/ther.2014.0007

Jentzer, J. C., Clements, C. M., Wright, R. S., White, R. D., \& Jaffe, A. S. (2016). Improving survival from cardiac arrest: A review of con- temporary practice and challenges. Annals of Emergency Medicine, 68(6), 678-689. doi: 10.1016/j.annemergmed.2016.05.022

Karnatovskaia, L. V., Wartenberg, K. E., \& Freeman, W. D. (2014). Therapeutic hypothermia for neuroprotection: History, mechanisms, risks, and clinical applications. Neurohospitalist, 4(3), 153-163. doi:10.1177/1941874413519802

Ketilsdottir, A., Albertsdottir, H. R., Akadottir, S. H., Gunnarsdottir, T. J., \& Jonsdottir, H. (2014). The experience of sudden cardiac arrest: Becoming reawakened to life. European Journal of Cardiovascular Nursing, 13(5), 429-435. doi:10.1177/ 1474515113504864

Koller, A. C., Rittenberger, J. C., Repine, M. J., Morgan, P. W., Kristan, J., \& Callaway, C. W. (2017). Comparison of three cognitive exams in cardiac arrest survivors. Resuscitation, 116, 98-104. doi:10.1016/ j.resuscitation.2017.04.011

Lilja, G., Nielsen, N., Friberg, H., Horn, J., Kjaergaard, J., Pellis, T., \& Cronberg, T. (2015). Long-term neurological outcome of out-ofhospital cardiac arrest survivors. Neurocritical Care, 23(Suppl. 1), 12.

Lim, C., Alexander, M. P., LaFleche, G., Schnyer, D. M., \& Verfaellie, M. (2004). The neurological and cognitive sequelae of cardiac arrest. Neurology, 63(10), 1774-1778. doi:10.1212/01.WNL.0000144189.83077.8E

Lippi, G., Aloe, R., Numeroso, F., \& Cervellin, G. (2011). The significance of protein $\mathrm{S}-100 \mathrm{~B}$ testing in cardiac arrest patients. Clinical Biochemistry, 44(8), 567-575. doi:10.1016/j.clinbiochem.2011.03.133

Lundgren-Nilsson, Å., Rosén, H., Hofgren, C., \& Sunnerhagen, K. S. (2005). The first year after successful cardiac resuscitation: Function, activity, participation and quality of life. Resuscitation, 66(3), 285-289. doi:10.1016/ j.resuscitation.2005.04.001

Mak, M., Moulaert, V. R. M., Pijls, R. W., \& Verbunt, J. A. (2016). Measuring outcome after 
cardiac arrest: Construct validity of Cerebral Performance Category. Resuscitation, 100, 610. doi:10.1016/j.resuscitation.2015.12.005

Mehra, R. (2007). Global public health problem of sudden cardiac death. Journal of Electrocardiology, 4O(6), S118-S122. doi:10.1016/j.jelectrocard.2007.06.023

Middelkamp, W., Moulaert, V. R., Verbunt, J. A., van Heugten, C. M., Bakx, W. G., \& Wade, D. T. (2007). Life after survival: Long-term daily life functioning and quality of life of patients with hypoxic brain injury as a result of a cardiac arrest. Clinical Rehabilitation, 21(5), 425-431. doi:10.1177/0269215507075307

Moulaert, V., van Heugten, C. M., Winkens, B., Bakx, W., de Krom, M., Gorgels, A., . . . Verbunt, J. (2013). New psychosocial intervention improves quality of life after cardiac arrest: Results of a randomised controlled trial. Resuscitation, 84(1), S1-S2. doi:10.1016/j.resuscitation.2013.08.020

Moulaert, V. R., Goossens, M., Heijnders, I. L., Verbunt, J. A., \& van Heugten, C. M. (2016). Early neurologically focused follow-up after cardiac arrest is cost-effective: A trialbased economic evaluation. Resuscitation, 106, 30-36. doi:10.1016/j.resuscitation. 2016.06.015

Moulaert, V. R., van Heugten, C. M., Gorgels, T. P., Wade, D. T., \& Verbunt, A. (2017). Long-term Outcome after survival of a cardiac arrest: A prospective longitudinal cohort study. Neurorehabilitation and Neural Repair, 31(6), 530-539. doi:10.1177/1545968317697032

Moulaert, V. R., van Heugten, C. M., Winkens, B., Bakx, W. G., de Krom, A., Gorgels, T. P., . . Verbunt, J. (2015). Early neurologically-focused follow-up after cardiac arrest improves quality of life at one year: A randomised controlled trial. International Journal of Cardiology, 193, 8-16. doi:10.1016/j.ijcard. 2015.04.229

Moulaert, V. R., Verbunt, J. A., van Heugten, C. M., \& Wade, D. T. (2009). Cognitive impairments in survivors of out-of-hospital cardiac arrest: A systematic review. Resus- citation, 80(3), 297-305. doi:10.1016/ j.resuscitation.2008.10.034

Mozaffarian, D., Benjamin, E. J., Go, A. S., Arnett, D. K., Blaha, M. J., . . . Howard, V. J. (2016). Heart disease and stroke statistics 2016 update. Circulation, 133(4), e38-e360. doi:10.1161/CIR.0000000000000350

Nichol, G., Guffey, D., Stiell, I. G., Leroux, B., Cheskes, S., Idris, A., \& Rea, T. D. (2015). Post-discharge outcomes after resuscitation from out-of-hospital cardiac arrest: A ROC PRIMED substudy. Resuscitation, 93, 74-81. doi:10.1016/j.resuscitation.2015.05.011

Nolan, J. P., Perkins, G. D., \& Soar, J. (2015). Improving survival after out-of-hospital cardiac arrest. The British Medical Journal, 351(h4989), 1-2. doi:10.1136/bmj.h4989

Nunes, B., Pais, J., Garcia, R., Magalhães, Z., Granja, C., \& Silva, M. C. (2003). Cardiac arrest: Long-term cognitive and imaging analysis. Resuscitation, 57(3), 287-297. doi:10.1016/S0300-9572(03)00033-9

Ong, M. E. H., Do Shin, S., De Souza, N. N. A., Tanaka, H., Nishiuchi, T., Song, K. J., Sarah, A. K. (2015). Outcomes for out-ofhospital cardiac arrests across 7 countries in. Asia: The Pan Asian Resuscitation Outcomes Study (PAROS). Resuscitation, 96, 100-108. doi:10.1016/j.resuscitation.2015.07.026

Ørbo, M., Aslaksen, P. M., Larsby, K., Norli, L., Schäfer, C., Tande, P. M., \& Anke, A. (2014). Determinants of cognitive outcome in survivors of out-of-hospital cardiac arrest. Resuscitation, 85(11), 1462-1468. doi:10.1016/j.resuscitation.2014.08.010

Perez, C. A., Samudra, N., \& Aiyagari, V. (2016). Cognitive and functional consequence of cardiac arrest. Current Neurology and Neuroscience Reports, 16(8), 1-10. doi:10.1007/s11910-016-0669-y

Peters, M. D., Godfrey, C. M., Khalil, H., McInerney, P., Parker, D., \& Soares, C. B. (2015). Guidance for conducting systematic scoping reviews. International Journal of Evidence-Based Healthcare, 13(3), 141-146. doi:10.1097/XEB.0000000000000050 
Polanowska, K. E., Sarzyńska-Długosz, I. M., Paprot, A. E., Sikorska, Ś., Seniów, J. B., Karpiński, G., \& Członkowska, A. (2014). Neuropsychological and neurological sequelae of out-of-hospital cardiac arrest and the estimated need for neurorehabilitation: A prospective pilot study. Kardiologia Polska (Polish Heart Journal), 72(9), 814-822. doi:10.5603/KP.a2014.0087

Prohl, J., Bodenburg, S., \& Rustenbach, S. J. (2009). Early prediction of long-term cognitive impairment after cardiac arrest. Journal of the International Neuropsychological Society, 15(3), 344-353. doi: 10.1017/S1355617709090493

Prohl, J., Röther, J., Kluge, S., de Heer, G., Liepert, J., Bodenburg, S., . . . Kreymann, G. (2007). Prediction of short-term and long-term outcomes after cardiac arrest: A prospective multivariate approach combining biochemical, clinical, electrophysiological, and neuropsychological investigations. Critical Care Medicine, 35(5), 1230-1237. doi:10.1097/01.CCM.0000261892.10559.85

Pusswald, G., Fertl, E., Faltl, M., \& Auff, E. (2000). Neurological rehabilitation of severely disabled cardiac arrest survivors. Part II. Life situation of patients and families after treatment. Resuscitation, 47(3), 241-248. doi:10.1016/S0300-9572(00)00240-9

Rittenberger, J. C., Raina, K., Holm, M. B., Kim, Y. J., \& Callaway, C. W. (2011). Association between Cerebral Performance Category, Modified Rankin Scale, and discharge disposition after cardiac arrest. Resuscitation, 82(8), 1036-1040. doi:10.1016/j.resuscitation.2011.03.034

Steinbusch, C. V., van Heugten, C. M., Rasquin, S. M., Verbunt, J. A., \& Moulaert, V. R. (2017). Cognitive impairments and subjective cognitive complaints after survival of cardiac arrest: A prospective longitudinal cohort study. Resuscitation, 120, 132-137. doi:10.1016/j.resuscitation.2017.08.007

Sulzgruber, P., Kliegel, A., Wandaller, C., Uray, T., Losert, H., Laggner, A. N., \& Kliegel, M. (2015). Survivors of cardiac arrest with good neurological outcome show considerable impairments of memory functioning. Resuscitation, 88, 120-125. doi:10.1016/j.resuscitation.2014.11.009

Tiainen, M., Poutiainen, E., Oksanen, T., Kaukonen, K. M., Pettilä, V., Skrifvars, M., \& Castrén, M. (2015). Functional outcome, cognition and quality of life after out-of-hospital cardiac arrest and therapeutic hypothermia: Data from a randomized controlled trial. Scandinavian Journal of Trauma, Resuscitation and Emergency Medicine, 23(1), 12. doi:10.1186/s13049-014-0084-9

Torgersen, J., Strand, K., Bjelland, T. W., Klepstad, P., Kvåle, R., Søreide, E., \& Flaatten, H. (2010). Cognitive dysfunction and health related quality of life after a cardiac arrest and therapeutic hypothermia. Acta Anaesthesiologica Scandinavica, 54(6), 721-728. doi:10.1111/j.1399-6576. 2010.02219.x

Whitehead, L., Perkins, G., Biggerstaff, D., Couper, K., \& Haywood, K. (2015). Exploring the lived experience of surviving an out of hospital cardiac arrest: Understanding what health outcomes really matter to patients. Resuscitation, 96(Suppl. 1), 108. doi:10.1016/j.resuscitation.2015.09.255

Disclosure. The authors have no relevant financial interest or affiliations with any commercial interests related to the subjects discussed within this article. 